\title{
Becoming a tobacco-free campus: A survey of student attitudes, opinions and behaviors
}

\author{
Rose M. Pignataro' ${ }^{1}$ Charles Daramola ${ }^{2}$
}

\begin{abstract}
INTRODUCTION The effectiveness of tobacco-free campus policies in preventing and mitigating tobacco use relies on students' perceptions, opinions, and adherence to clean-air restrictions. The purpose of this study was to gather data regarding student attitudes, opinions and tobacco use behaviors, one year following implementation of the tobacco-free campus initiative.

METHODS Data were gathered using an anonymous, online survey of graduate and undergraduate students at a public university, one year following implementation of a tobacco-free campus policy. Survey items included tobacco use behaviors, nicotine dependence, opinions towards the policy, challenges in policy adherence among tobacco users, and awareness of tobacco cessation resources for students. Analysis primarily included descriptive statistics.

RESULTS Of 108 respondents, only 18 were habitual tobacco users with most using: cigarettes, cigars or cigarillos (38\%), vaping (17.8\%), hookah $(11.9 \%)$, and smokeless tobacco $(11.9 \%)$. Several reported multiple use. Common motives for tobacco use were relaxation and mood regulation. Tobacco users rated a moderate level of difficulty in adhering to the policy. Only half of the total respondents were aware of cessation resources, specifically peer counseling. Most tobacco users $(71 \%)$ believed that they could quit without assistance.

Conclusions Preliminary data show $21.8 \%$ prevalence of tobacco use within the sample. Information on student opinions and behaviors, including lower risk perception, dual use, and lack of awareness of cessation resources can inform more effective prevention and mitigation strategies, in addition to the tobaccofree campus policy. Further research is needed to monitor policy adherence and changes in student tobacco behaviors.
\end{abstract}

\section{AFFILIATION}

1 School of Health Sciences, Emory and Henry College, Marion, United States

2 Department of Public Health

Science, Bakersfield College,

Bakersfield, United States

\section{CORRESPONDENCE TO}

Rose M. Pignataro. School of Health Sciences, Emory and Henry College, 565 Radio Hill Road, Marion, VA 24354, United States. E-mail: rpignataro@ehc.edu ORCID ID: https://orcid.org/0000-00033588-9818

\section{KEYWORDS}

tobacco cessation, tobacco policy, student health, clean-air restrictions

Received: 5 May 2020
Revised: 27 July 2020
Accepted: 31 July 2020

\section{INTRODUCTION}

In 2011, the American College Health Association endorsed a total ban on indoor and outdoor use of tobacco on college campuses. These recommendations reflect data demonstrating that college-aged adults have one of the highest rates of tobacco use (SAMSHA) with an estimated prevalence of $21.4 \%{ }^{1}$. Many college students experiment with tobacco or initiate use; $99 \%$ of adult smokers start before the age of 26 years $^{1}$. College-aged individuals are also more likely to use alternative tobacco products such as electronic cigarettes and hookah ${ }^{2,3}$. Motives for using tobacco include improved self-confidence, alleviating boredom, reducing stress, regulating mood, and social interaction ${ }^{2,4}$. Certain forms of tobacco, such as hookah, may also be viewed as less harmful and less addictive $^{5}$. Research shows that tobacco-free policies may reduce initiation and continued use ${ }^{6}$.

Among college students, barriers to tobacco cessation may differ from older users and include: low interest in cessation, a lack of awareness of cessation resources ${ }^{7}$, less likelihood of seeking 
outside assistance ${ }^{8}$, lower risk perceptions, and environmental cues that support tobacco use $\mathrm{e}^{9}$. Research shows that tobacco-free campus policies may reduce initiation and promote cessation ${ }^{6}$. However, adherence and effectiveness of these policies are contingent upon students' perceptions regarding the value of tobacco use and the relative benefits of a tobacco-free environment ${ }^{2}$. Although many faculty, staff and students support a ban on cigarette smoking on campus, a complete ban on all tobacco products, including electronic cigarettes and smokeless tobacco, has been somewhat more controversial $^{10,11}$. At Florida Gulf Coast University, where this study took place, the smoke and tobacco free campus policy was enacted at the start of the 2016-2017 academic year. In addition to combustible tobacco products like cigarettes, cigars, and cigarillos, the guidelines encompass electronic smoking devices (e.g. e-cigarettes), hookah, and smokeless tobacco ${ }^{12}$. The rationale for a total ban on tobacco products reflects evidence concerning the adverse effects of nicotine for all routes of administration ${ }^{12}$. The policy extends to all members of the campus community: students, faculty, staff, and visitors. Violation is subject to discipline pursuant to the Student Code of Conduct or employee disciplinary action delineated in the collective bargaining agreement. No specific plans for enforcement or compliance monitoring were included in the guidelines.

The purpose of this study was to gain information about tobacco use behaviors and students' opinions and attitudes towards the tobacco-free campus policy, one year following its implementation. This information will assist in planning tobacco prevention and cessation strategies that supplement and support clean-air restrictions at the university.

\section{METHODS}

Data were obtained using an anonymous, online survey. The small convenience sample $(n=108)$ consisted of full-time graduate or undergraduate students, aged 18 years and older, enrolled in the 2017-2018 academic year. Participants were recruited via electronic mail (one initial mailing and two reminders) and two in-person solicitations at the student union using iPads for onsite survey completion.

Within the survey, demographic information included age, sex, race/ethnicity, and year of study. Respondents who used tobacco answered questions regarding the type, intensity, and frequency of use, and the use of multiple products ${ }^{6,13}$. Items also included motives for tobacco use $\mathrm{e}^{14}$ and intention to quit based on the Stages of Change ${ }^{15}$, as well as confidence in ability to quit and self-perceptions of possible nicotine addiction ${ }^{16}$. All students (tobacco users and non-users) were also asked about their opinions towards the tobacco-free campus policy and awareness of free cessation assistance provided by the College of Health Sciences and Student Health Services.

Data were analyzed using the Checkbox ${ }^{\circledR}$ survey platform and SPSS (Statistical Package for Social Sciences) version 24, a product of IBM Corporation, Armonk, New York (2016). Descriptive statistics included frequency and percentages. Due to the small sample size, the chi-squared test of independence was used to compare sample demographics to characteristics of the university student body as a whole. Logistic regression was used to examine associations between tobacco use and respondent characteristics (sex, race/ethnicity, year of study, intent to quit, and social versus solitary use). There were insufficient data to support multivariate regression. Bivariate correlations were calculated to test associations between dosage of tobacco use and difficulty in quitting, as well as the association between self-perceptions of possible nicotine dependence and difficulty in quitting. Qualitative data from open-ended survey responses were analyzed using narrative review to identify emergent themes.

\section{RESULTS}

The sample consisted of $66.7 \%$ female and $33.3 \%$ male respondents. The majority were White, nonHispanic ( $71.72 \%$ ), with $12.1 \%$ Black/African American, 11.1\% Hispanic/Latinx, and 3\% Asian/ Pacific Islander. Distribution of students, in the total sample, according to year of study was as follows: year one $3 \%$, year two $10.2 \%$, year three $30.6 \%$, and year four $42.9 \%$ of undergraduate studies; and graduate students $13.3 \%$. Despite the small number of respondents, results of the chi-squared test of 
independence comparing the student body as a whole to characteristics of the sample showed no statistically significant differences in graduate versus undergraduate enrollment $(\mathrm{p}=0.16)$, sex $(\mathrm{p}=0.16)$ or race/ethnicity $(\mathrm{p}=0.28)$.

Eighteen participants (21.4\%) self-identified as tobacco/nicotine users. However, 33 respondents completed questions reflecting motives for tobacco use based on periodic as well as habitual use. This is consistent with research showing that younger adults may not self-identify as tobacco users if they only use tobacco on an intermittent basis ${ }^{2}$. Most respondents reported the use of combustibles, i.e. cigarettes, cigars or cigarillos (38\%) followed by electronic cigarettes/vaping (17.8\%), hookah (11.9\%), and smokeless tobacco (11.9\%). Several students reported multiple forms of tobacco use, consistent with previous data showing over $10 \%$ of adults in the United States report using more than one type of tobacco product ${ }^{17}$. Motives for tobacco use are summarized in Table 1 . The most prevalent motives were relaxation and mood regulation.

The ability to conduct multivariate regression was limited by the small sample size. Using logistic regression and bivariate analyses, no statistically significant associations were found between demographic variables and likelihood of tobacco use, tobacco habits, self-perceived nicotine dependence, or difficulty in quitting $(\mathrm{p}<0.05)$.

Qualitative analysis of open-ended responses revealed that several students felt that there was minimal risk associated with being a social smoker, and that the benefits of tobacco use as a source of pleasure or as a coping method outweighed potential risks. Resistance to peer counseling included beliefs that users could quit 'if they really wanted to', and that you 'can't help someone who don't want help'. Other respondents expressed that peer counseling alone might not be adequate for someone with nicotine dependence. Additional feedback from tobacco users indicated some objection to the tobacco-free campus policy, including the perception that it created hostility towards smokers and that 'vaping isn't technically tobacco or smoke' and should be allowed. Other tobacco users stated that the policy was a violation of students' rights and was unfair to people who live on campus since other adults are generally permitted to smoke in their place of residence.

\section{Limitations and strengths}

Given the total student population at this particular university (15000), this study uses a very small convenience sample, limiting the ability to compare associations between patterns of tobacco use and demographic variables. Additionally, the survey was only designed to look at student opinions and tobacco use behaviors. Self-reported adherence to the new policy was not assessed.

Despite these limitations, valuable information regarding tobacco use patterns and risk perceptions, as well as the lack of awareness of available cessation resources, assists in guiding future efforts to prevent and reduce student tobacco use. Baseline data

Table 1. Motives for using tobacco ( $\mathrm{N}=33)$

\begin{tabular}{|c|c|c|c|c|c|}
\hline Statement & $\begin{array}{l}\text { Strongly } \\
\text { agree } \\
n(\%)\end{array}$ & $\begin{array}{l}\text { Agree } \\
n(\%)\end{array}$ & $\begin{array}{c}\text { Neither agree } \\
\text { nor disagree } \\
n(\%)\end{array}$ & $\begin{array}{l}\text { Disagree } \\
n(\%)\end{array}$ & $\begin{array}{c}\text { Strongly } \\
\text { disagree } \\
n(\%)\end{array}$ \\
\hline Using tobacco helps me fit in with other people & 0 & $1(3.0)$ & $10(30.0)$ & $9(27.3)$ & $13(39.4)$ \\
\hline Using tobacco helps me feel more confident & 0 & $4(12.1)$ & 9 (27.3) & $9(27.3)$ & $10(30.0)$ \\
\hline Using tobacco is something to do when I feel bored & $1(3.0)$ & $10(30.3)$ & $8(24.2)$ & $5(15.2)$ & $9(27.3)$ \\
\hline When I am angry, using tobacco helps me calm down & $5(15.2)$ & $7(21.2)$ & $8(24.2)$ & $4(12.1)$ & $9(27.3)$ \\
\hline If I am feeling irritable, using tobacco helps me relax & $6(18.2)$ & $9(27.3)$ & $7(21.2)$ & $3(9.0)$ & $8(24.2)$ \\
\hline $\begin{array}{l}\text { When I am upset about something, tobacco helps me } \\
\text { cope }\end{array}$ & $4(12.1)$ & $9(27.3)$ & $8(24.2)$ & $3(9.0)$ & $9(27.3)$ \\
\hline Using tobacco helps me keep my weight down & $2(6.1)$ & $1(3.0)$ & 6 (18.2) & $10(30.0)$ & 13 (39.4) \\
\hline $\begin{array}{l}\text { Other people judge me or criticize me because I use } \\
\text { tobacco }\end{array}$ & 5 (15.2) & 6 (18.2) & $12(36.4)$ & $5(15.2)$ & $5(15.2)$ \\
\hline
\end{tabular}


reflecting prevalence and motives for tobacco use can be used to plan and assess future prevention and cessation strategies.

\section{CONCLUSIONS}

Similar to prior studies, our survey respondents underestimated health risks associated with tobacco as well as its addictive properties, leading many users to indicate that they could quit at any time without much assistance. In addition, some respondents indicated lower perceived vulnerability compared with the benefits of tobacco use as a coping strategy. Study results should be used to tailor prevention and health education by including information about the health risks of alternative forms of tobacco and intermittent use, including potential addiction. Furthermore, better marketing for available cessation resources is necessary to promote student participation. Prior research indicates that adherence to tobacco-free campus policies is enhanced when cessation services are provided, including those designed to help students manage nicotine dependence ${ }^{11}$. Future studies, including long-term follow-up, are recommended to measure the impact of the tobacco-free campus policy on student tobacco use, and whether opinions and attitudes towards the policy change over time. Another factor that should be included is the effect of non-enforcement of the policy, lack of penalties, and rates of compliance ${ }^{18}$.

\section{REFERENCES}

1. Wang T, Tynan M, Hallett C, et al. Smoke-free and tobacco-free policies in colleges and universities - United States and territories. MMWR. 2017;67(24):686-689. doi:10.15585/mmwr.mm6724a4

2. Berg C, Lung P, Hayes R, et al. Smoking frequency among current college student smokers: Distinguishing characteristics and factors related to readiness to quit smoking. Health Educ Res. 2012;27(1):141-150. doi:10.1093/her/cyr106

3. Latimer L, Batanova M, Loukas A. Prevalence and harm perceptions of various tobacco products among college students. Nicotine Tob Res. 2014;16(5):519-526. doi:10.1093/ntr/ntt174

4. Schleicher H, Harris K, Cately D, Nazir N. The role of depression and negative affect regulation expectancies in tobacco smoking among college students. J Am Coll Health. 2009;57(5):507-512. doi:10.3200/jach.57.5.507512

5. Akl E, Jawad M, Lam W, Co C, Obeid R, Irani J. Motives, beliefs and attitudes towards waterpipe smoking: A systematic review. Harm Reduc J. 2013;10(1):12. doi:10.1186/1477-7517-10-12

6. Berg C, Lessard L, Pareklar P, et al. College student reactions to smoking bans in public, on campus and at home. Health Educ Res. 2011;26(1):106-118. doi:10.1093/her/cyq076

7. Hughes J, Cohen B, Callas P. Treatment seeking for smoking cessation among young adults. J Subst Abuse Treat. 2009;37(2):211-213. doi:10.1016/j. jsat.2008.11.006

8. Solberg L, Boyle R, McCarty M, Asche S, Theole M. Young adult smokers: Are they different? Am J Manag Care. 2007;31(4):353-362. PMID:17988188.

9. Staten R, Noland M, Rayens M, Hahn E, Dignan M, Ridner S. Social influences on cigarette initiation among college students. Am J Health Behav. 2007;31(4): 353-362. doi:10.5993/ajhb.31.4.2

10. Bartington SE, Wootton R, Hawkins P, Farley A, Jones L, Haroon S. Smoking behaviours and attitudes towards campus-wide tobacco control policies among staff and students: A cross-sectional survey at the University of Birmingham. BMC Public Health. 2020;20(1):252. doi:10.1186/s12889-020-8321-9

11. Braverman M, Hoogesteger L, Johnson J, Aaron L. Supportive of a smoke-free campus but opposed to a $100 \%$ tobacco-free campus: Identification of predictors among university students, faculty, and staff. Prev Med. 2017;94:20-26. doi:10.1016/j.ypmed.2016.10.021

12. Florida Gulf Coast University. Policy 3.048 Smoke Free and Tobacco Free Campus. https://www.fgcu.edu/ generalcounsel/policies/approved/policy3.048.pdf. Published 2016. Accessed July 27, 2020.

13. Loukas A, Chow S, Pasch K, et al. College students' polytobacco use, cigarette cessation, and dependence. Am J Health Behav. 2016;40(4):514-522. doi:10.5993/ ajhb.40.4.13

14. Piasecki T, Richardson A, Smith S. Self-monitored motives for smoking among college students. Psychol Addict Behav. 2007;21(3):328-337. doi:10.1037/0893164x.21.3.328

15. Prochaska J, Velicer W. The Transtheoretical Model of Health Behavior Change. Am J Health Promot. 1997;12(1):38-48. doi:10.4278/0890-1171-12.1.38

16. Heatherton T, Kozlowski L, Frecker R, Fagerstrom K. The Fagerstrom Test for Nicotine Dependence: A revision of the Fagerstrom Tolerance Questionnaire. Br J Addict. 1991;86(9):1119-1127. doi:10.1111/j.1360-0443.1991. tb01879.x

17. Lee J, Purcell C, Chaney B. An experiment assessing punitive versus wellness framing of a tobacco-free campus policy on students' perceived level of university support. Int J Environ Res Public Health. 2017;14(8):938. doi:10.3390/ijerph14080938

18. Russette H, Harris K, Schuldberg D, Green L. Policy 
compliance of smokers on a tobacco-free university campus. J Am Coll Health. 2014;62(2):110-116. doi:10. $1080 / 07448481.2013 .854247$

\section{ACKNOWLEDGEMENTS}

The authors thank Jenna M. Stasi for her assistance with data collection.

\section{CONFLICTS OF INTEREST}

The authors have completed and submitted the ICMJE Form for Disclosure of Potential Conflicts of Interest and none was reported.

\section{FUNDING}

Funding for this project was provided through the Florida Physical Therapy Association, Linda Crane Grant, 2017.

\section{AUTHORS' CONTRIBUTIONS}

RMP and CD contributed to the concept, aim and scope of this study. Both authors contributed to survey development and validation, and assisted in the data collection. RMP completed data analysis and the manuscript draft. $\mathrm{CD}$ provided feedback and contributed in the editing of the manuscript.

PROVENANCE AND PEER REVIEW

Not commissioned; externally peer reviewed. 